\title{
A pilot study on the effect of a novel feed additive containing exogenous enzymes, acidifiers, sodium butyrate and silicon dioxide nanoparticles on selected cellular immune indices and body weight gains of calves
}

\author{
Ewelina Szacawa $^{1 凶}$, Katarzyna Dudek ${ }^{1}$, Dariusz Bednarek ${ }^{1}$, \\ Marek Pieszka² ${ }^{2}$, Dorota Bederska-Łojewska ${ }^{2}$ \\ ${ }^{1}$ Department of Cattle and Sheep Diseases, National Veterinary Research Institute, Puławy, Poland \\ ${ }^{2}$ Department of Animal Nutrition and Feed Science, National Research Institute of Animal Production, Balice, Poland \\ ewelina.szacawa@piwet.pulawy.pl
}

Received: June 28, $2021 \quad$ Accepted: November 30, 2021

\begin{abstract}
Introduction: The rearing of calves is a difficult period for farmers due to health problems to which the animals are prone this time. Since the use of antibiotics as growth promoters has been forbidden, various innovative feed additives have been tested in many countries around the world. Material and Methods: In this study, experimental (E) calves were supplemented with a novel feed additive consisting of the pancreatic-like enzymes protease and lipase, a fat-coated mixture of organic fumaric, malic, citric and sorbic acids, sodium butyrate and silicon dioxide nanoparticles. Control (C) calves received feed without additive. During the supplementation, white blood cell (WBC) counts with leukocyte differentiation, percentages of B lymphocytes and $\mathrm{T}$ lymphocytes and their subpopulations, phagocytic activity and oxidative burst of circulating monocytes and granulocytes were examined. Body weight (b.w.) gains of the calves were also monitored. Results: The WBC counts in the $\mathrm{E}$ and $\mathrm{C}$ calves were within the reference ranges throughout the study. In the analysis of the percentages of the lymphocyte subpopulations, phagocytic activity and oxidative burst, no statistically significant differences were reported between the $\mathrm{E}$ and $\mathrm{C}$ groups. However, higher average daily body weight gains were obtained for the E calves. Conclusion: The study revealed that the examined feed additive did not modulate the immune response of the calves significantly. The tendency to higher daily average b.w. gains in the E calves than in the $\mathrm{C}$ calves suggests a beneficial effect of this feed additive.
\end{abstract}

Keywords: calves, feed additive, immune response, average daily body weight gains.

\section{Introduction}

In the early stage of calves' lives, physiological changes take place in the digestive tract and can be caused by different feeding conditions and altered capacity to use nutrients in the diet. The change to a solid diet that contains fibre can cause stress and health problems as a result, e.g. diarrhoea $(2,22)$ and bovine respiratory syndrome, in which different species of bacteria $(7,33,37)$ and viruses $(3)$ can be involved. In the same period, the immune system is immature and is beginning to develop in two distinct directions referred to as innate and acquired immunity. It produces an immune response that is diverse and sensitive and is able to recognise and eliminate pathogens. The occurrence of infections in a herd's calves often causes significant economic losses in the cattle industry due to increased costs of treatment and the low growth rate of the animals. At this stage of breeding, the prevention of disease and improvement of general health status is important. Since the use of antibiotics as growth promoters has been forbidden in the feeding of cattle due to the increasing antibiotic resistance of enteric bacteria, alternative additives with similar features in animal nutrition are being examined by scientists. The most important reason for antibiotic use is their impact on the gastrointestinal microbiota of calves and the resulting superior performance (17). Unfortunately, antimicrobial resistance emerged after extensive usage of antimicrobials to achieve better growth parameters. Subsequently, the clinical effectiveness of antibiotics in animals and in humans worsened (1). 
Organic acids are among the substances used for the replacement of antibiotics in cattle feed because their basic purpose is to maintain an optimal $\mathrm{pH}$ in the digestive tract content. This is especially important in the case of young animals in which the gastrointestinal tract is just beginning to develop. The use of acidifiers instead of antibiotics is recommended to prevent one of the most common problems that cattle breeders face: calf diarrhoea. The bacteriostatic effect of acidifiers can improve animal growth and feed efficiency (32). Lower $\mathrm{pH}$ values are optimal for digestive enzymes and thus improve nutrient digestibility, which leads to the higher body weight (b.w.) gains in animals supplemented with acidifiers (5). The digestive tract of the young calf is deficient in proteolytic and amylolytic enzymes, and that is why they are broadly used in animal feeding to support the pancreatic secretory function. The enzymes which assist digestion in calves can be microbe delivered. The advantage of such a delivery mode is that the enzymes can be used in lower doses and have a broader $\mathrm{pH}$ range of activity (34). Additionally, they may reduce undigested feed components, which protects the gastrointestinal tract against inflammatory changes caused by proteinaceous antinutrients and leads to higher b.w. gains $(4,9,40)$.

The health of the calf gastrointestinal tract may also be supported by sodium butyrate, specifically as a contributor to its normal maturation. Butyrate belongs to the group of volatile fatty acids (VFA) produced in the rumen by bacterial fermentation of carbohydrates (12). Sodium butyrate is the most frequently used source of dietary butyrate (20). Besides supporting the maturation of the gastrointestinal tract, it facilitates feed digestion, which may have a synergistic effect on animal growth (26). There are suggestions that treatment including butyrate may modulate the humoral immune response of calves (13)

Another interesting alternative to antibiotic growth stimulants are silicon dioxide nanoparticles, due to their bactericidal and toxin-binding activities as shown by previous research (30). Over the last few years, there has been growing interest in nanoparticles. Their main advantages are their high surface-to-volume ratio, unique features of surface modification and the facility of engineering them to obtain particles of various sizes and shapes and different chemical characteristics $(6,25)$. Nanoparticles are a valuable line of research in farm animal feed science because they are used mainly as an alternative to preservatives that have impact on the intestinal pathogenic microbiota (27). Their use to enhance the properties of feed and improve the delivery of orally administered drugs has become common, but the potential health effects of these ingested nanomaterials have still not been investigated sufficiently.

In this study, experimental calves were supplemented with a novel feed additive that contained pancreatic-like enzymes of microbial origin (protease and lipase), a fat-coated mixture of the organic fumaric, malic, citric and sorbic acids, sodium butyrate and silicon dioxide nanoparticles $\left(\mathrm{nSiO}_{2}\right)$. The aim of this study was to evaluate the effect of the novel feed additive on average daily gains (ADG) and alterations in the immunological parameters of the calves. For this purpose, the b.w. of the calves was monitored and peripheral blood was collected to determine white blood cell (WBC) counts with leukocyte differentiation, particularly counts of lymphocytes (LYM), monocytes (MON), and granulocytes (GRA). In addition, the cytometric immunophenotyping of $\mathrm{T}$ lymphocytes (expressing $\mathrm{CD}^{+}$surface antigens), $\mathrm{T}$ helper lymphocytes $\left(\mathrm{CD}^{+}\right), \mathrm{T}$ cytotoxic/suppressors $\left(\mathrm{CD} 8^{+}\right)$ and $\mathrm{B}$ lymphocytes $\left(\mathrm{WC}^{+}\right)$and the phagocytic activity and oxidative burst of circulating monocytes and granulocytes were measured.

\section{Material and Methods}

Animals and treatments. The experiment was conducted on six clinically healthy Holstein-Friesian female calves at the age of 4-8 weeks. They were kept in the vivarium of the National Veterinary Research Institute in Puławy, Poland. Before the experiment, the animals were randomly assigned to the experimental (E) $(n=3)$ and control $(C)$ groups $(n=3)$ and housed in two pens with free access to water. The basic diet of all calves from week 0 (the start of the administration of feed additive) to week 3 of the experiment included $312.5 \mathrm{~g}$ of milk replacer and from weeks 4 to $7,375 \mathrm{~g}$ of milk replacer and $500 \mathrm{~g}$ of mixed calf protein feed twice per day. In addition, every calf from the E group was individually orally supplemented with a dose of the feed additive given with the portion of milk replacer once per day for the seven weeks of the study. It contained pancreatic-like enzymes of microbial origin which were protease $(18 \mathrm{mg})$ and lipase $(45 \mathrm{mg})$, a fat-coated mixture of organic acids which comprised fumaric $(250 \mathrm{mg})$, malic $(250 \mathrm{mg})$, citric $(120 \mathrm{mg})$ and sorbic $(220 \mathrm{mg})$ acids, sodium butyrate $(15 \mathrm{mg})$, and $\mathrm{nSiO}_{2}$ $(3,000 \mathrm{mg})$ with a particle size of 5-10 nm and absorption area of $380 \mathrm{~m}^{2} / \mathrm{g}$ (A300, Evonik, Essen, Germany). The calves from the $\mathrm{C}$ group were not supplemented with the feed additive. All calves also received hay and water ad libitum. A detailed breakdown of the nutrient composition of the diet is shown in Table 1.

During the study period, the amount of feed intake, rectal temperature, and overall health status of the calves were recorded on a daily basis. The b.w. gains were monitored once a week before the morning feeding until the end of the study (week 7). Blood samples were taken from the vena jugularis externa once per week: before the beginning of the administration of the feed additive and seven times during its administration at weekly intervals. To minimise the distress of the calves, the blood was drawn from each animal using a single needle insertion. Whole blood samples collected in $1 \mathrm{~mL}$ 
vacutainer tubes with $\mathrm{K}_{2}$-EDTA as the anticoagulant (Medlab, Raszyn, Poland) were used for WBC counts and lymphocyte subpopulation percentage analyses. Additionally, samples collected in $2.5 \mathrm{~mL}$ vacutainer tubes with heparin as the anticoagulant (Medlab) were used for the phagocytic activity and oxidative burst analysis. All the samples were examined within $1 \mathrm{~h}$ of collection.

Table 1. Ingredient and nutrient composition of the calves' basal diet

\begin{tabular}{|c|c|}
\hline Ingredient & Value \\
\hline \multicolumn{2}{|l|}{ Milk replacer } \\
\hline Crude protein $(\%)$ & 20.0 \\
\hline Crude oils and fats (\%) & 8.0 \\
\hline Ash (\%) & 6.0 \\
\hline Crude fibre (\%) & 1.3 \\
\hline Calcium (\%) & 0.7 \\
\hline Phosphorus (\%) & 0.45 \\
\hline Sodium $(\%)$ & 0.1 \\
\hline Lysine (\%) & 1.4 \\
\hline Vitamin A (IU/kg) & 10,000 \\
\hline Vitamin $\mathrm{D}_{3}(\mathrm{IU} / \mathrm{kg})$ & 2,000 \\
\hline Vitamin $E(\mathrm{mg} / \mathrm{kg})$ & 80 \\
\hline Vitamin $K_{3}(\mathrm{mg} / \mathrm{kg})$ & 1.0 \\
\hline Vitamin B1 (mg/kg) & 4.3 \\
\hline Vitamin B2 (mg/kg) & 4.3 \\
\hline Vitamin B6 (mg/kg) & 4.3 \\
\hline Vitamin C $(\mathrm{mg} / \mathrm{kg})$ & 100 \\
\hline Niacinamide $(\mathrm{mg} / \mathrm{kg})$ & 6.6 \\
\hline Calcium D-pantothenate $(\mathrm{mg} / \mathrm{kg})$ & 8.6 \\
\hline Folic acid $(\mathrm{mg} / \mathrm{kg})$ & 0.35 \\
\hline Vitamin B12 (mg/kg) & 0.05 \\
\hline Biotin (mg/kg) & 0.07 \\
\hline Choline chloride $(\mathrm{mg} / \mathrm{kg})$ & 300 \\
\hline Manganese $(\mathrm{mg} / \mathrm{kg})$ & 64 \\
\hline Zinc $(\mathrm{mg} / \mathrm{kg})$ & 56 \\
\hline Iron $(\mathrm{mg} / \mathrm{kg})$ & 80 \\
\hline Copper $(\mathrm{mg} / \mathrm{kg})$ & 8 \\
\hline Iodine (mg/kg) & 0.96 \\
\hline Selenium $(\mathrm{mg} / \mathrm{kg})$ & 0.2 \\
\hline Enterococcus faecium $(\mathrm{cfu} / \mathrm{kg})$ & $1.2 \times 10^{9}$ \\
\hline \multicolumn{2}{|l|}{ Mixed calf feed } \\
\hline Crude protein $(\%)$ & 18.5 \\
\hline Crude oils and fats (\%) & 3.3 \\
\hline Crude fibre max. $(\%)$ & 6.5 \\
\hline Crude ash max. $(\%)$ & 9.0 \\
\hline Phosphorus (\%) & 0.8 \\
\hline Calcium $(\%)$ & 1.3 \\
\hline Sodium (\%) & 0.23 \\
\hline Magnesium (\%) & 0.25 \\
\hline Vitamin A (IU/kg) & 25,000 \\
\hline Vitamin $\mathrm{D}_{3}(\mathrm{IU} / \mathrm{kg})$ & 5,000 \\
\hline Vitamin E (mg/kg) & 25.0 \\
\hline
\end{tabular}

cfu-colony forming unit

ADG of calves. The calves' b.w. was recorded before the start of feed additive administration (week 0 of the experiment) and then every week until week 7 of the experiment. The ADG was calculated as body weight at the end of the period - body weight at the beginning of the period $\times$ period duration in days ${ }^{-1}$.
Blood leukocyte counts. WBC with leukocyte differentiation which included LYM, MON, and GRA were counted in whole blood samples containing $\mathrm{K}_{2}$-EDTA using an Exigo automatic veterinary blood analyser (Boule Medical AB, Spånga, Sweden).

Immunophenotyping of lymphocytes. The percentages of lymphocyte subpopulations containing $\mathrm{CD} 2^{+}$surface antigens ( $\mathrm{T}$ lymphocytes), $\mathrm{CD} 4^{+}$( $\mathrm{T}$ helper lymphocytes), $\mathrm{CD}^{+}$( $\mathrm{T}$ cytotoxic/suppressor lymphocytes) and $\mathrm{WC4}^{+}$(B lymphocytes) were assessed in whole blood samples containing $\mathrm{K}_{2}$-EDTA. The tests were performed with an EPICS XL 4C flow cytometer (Beckman Coulter, Brea, CA, USA), using single-cell labelling according to Muszyńska et al. (24).

Phagocytic activity of granulocytes and monocytes. The phagocytic activity of the granulocytes and monocytes was determined in heparinised whole blood samples using a commercial Phagotest kit (Glycotope Biotechnology, Heidelberg, Germany) according to Wojcicka-Lorenowicz et al. (41) with modifications. The percentages of granulocytes and monocytes that had phagocytic activity against bacteria was evaluated, and the mean fluorescence intensity (MFI) of the phagocytising cell population was assessed to estimate the individual cellular phagocytic activity, i.e. the amount of bacteria ingested per cell. The samples were analysed with the EPICS XL 4C flow cytometer within $60 \mathrm{~min}$.

Oxidative burst of granulocytes and monocytes. The oxidative burst activity of the granulocytes and monocytes was examined in heparinised whole blood samples using a commercial Phagoburst kit (Glycotope Biotechnology, Heildelberg, Germany) according to Wojcicka-Lorenowicz et al. (41) with modifications. The samples were analysed by flow cytometry using the same device as previously described within $30 \mathrm{~min}$. The oxygen metabolism of the granulocytes and macrophages was determined using the percentage of cells phagocytising E. coli.

Statistical analysis. All values are presented as arithmetic means \pm standard deviation (SD). The results obtained for the experimental group were compared with the control group to determine statistical significance using Student's $t$-test with a statistical significance level of $\mathrm{P}<0.05$.

\section{Results}

ADG of calves. The calves from the $\mathrm{E}$ group consumed all portions of the novel feed additive intended for them. The ADG for the entire period of the experiment was $20 \pm 167 \mathrm{~g} /$ day in the $\mathrm{C}$ group and $231 \pm 130 \mathrm{~g} /$ day in the E group. The differences noted were not statistically significant $(\mathrm{P}<0.05)$.

Blood leukocyte counts. The results of the analysis of $\mathrm{WBC}$ and their subsets in the calves are presented in Fig. 1. The WBC and GRA counts in the E group were higher in week 2 and from weeks 4 to 7 of the 
experiment compared with the $\mathrm{C}$ group. The LYM counts had comparable values for both groups throughout the study, except for the values in the last week of the experiment, when the value for the E group was higher than that obtained for the $\mathrm{C}$ group. Slight differences were seen in the MON counts of the E group from those of the $\mathrm{C}$ group, i.e. they were lower in weeks 1 and 3 and higher in weeks 4 and 7 of the experiment. For all examined parameters, no statistically significant differences were found between the $\mathrm{E}$ and $\mathrm{C}$ groups and all results were within the reference ranges.

Immunophenotyping of lymphocytes. Cytometric determination of the percentage of lymphocyte subpopulations with $\mathrm{CD} 2^{+}$and $\mathrm{CD} 4^{+}$surface antigens in the peripheral blood of the calves revealed that the $\mathrm{E}$ group and $\mathrm{C}$ group percentages of these antigens were similar except for in the last week, when the values for the supplemented group were lower than those obtained for the control group. The percentage of the $\mathrm{CD}^{+}$lymphocyte subpopulation in the E group in weeks 1 and 6 of the study visibly decreased, but in week 7 it was slightly higher than that in the $\mathrm{C}$ group, and the percentage of the lymphocyte subpopulation expressing $\mathrm{WC}^{+}$in the E group up to week 3 and in the last week of the experiment had also lower values than that in the control calf group. In the remaining weeks, these values were comparable in both groups. No statistically significant differences in any examined lymphocyte subpopulations were found between the $\mathrm{E}$ and $\mathrm{C}$ groups throughout the experiment (Fig. 2).

Phagocytic activity of granulocytes and monocytes. Expressed as the percentage of phagocytic granulocytes, this activity in the $\mathrm{E}$ group was comparable to that in the $\mathrm{C}$ group, with the exception of weeks 6 and 7 of the experiment, when the values for the E group were higher than those for the $\mathrm{C}$ group, and weeks 1 and 5, when the values for the E group were lower than those for the $\mathrm{C}$ group. The MFI values for the phagocytic granulocytes of the E group were slightly higher for most of the study, i.e. in weeks 2, 3, 4 and 7, but lower in weeks 1,5 and 6 than the $C$ group values (Fig. 3A). No statistically significant differences were found between the $\mathrm{E}$ and $\mathrm{C}$ groups during the administration of the feed additive. The percentage of phagocytic monocytes for the E group was comparable to that of the $\mathrm{C}$ group, but slight differences were visible. These disparities were that in weeks 0,1 and 2 the values for the E group were lower than those for the control, whereas in weeks 6 and 7 the percentage of phagocytic monocytes was higher in the $\mathrm{E}$ group than in the $\mathrm{C}$ group. The MFI for monocytes in the $\mathrm{E}$ group was lower or equal to that of the $\mathrm{C}$ group; however, no significant $(\mathrm{P}<0.05)$ differences between the groups were observed (Fig. 3B).

Oxidative burst of granulocytes and monocytes in the peripheral blood of the calves. The results of the analysis of the oxidative burst activity of the granulocytes and monocytes after E. coli stimulation in the peripheral blood of the calves are presented in Fig. 4. The percentages of phagocytic cells showing oxidative burst activity were comparable in both groups, with the exception of weeks 1,3 and 4, when lower E group values were observed. The MFI of the granulocytes and monocytes after $E$. coli stimulation was generally higher throughout the study, except for weeks 1, 3 and 4, when the E group values were lower compared with those of the $\mathrm{C}$ group. No statistically significant differences were found between the $\mathrm{E}$ and C group oxidative burst activities throughout the study.
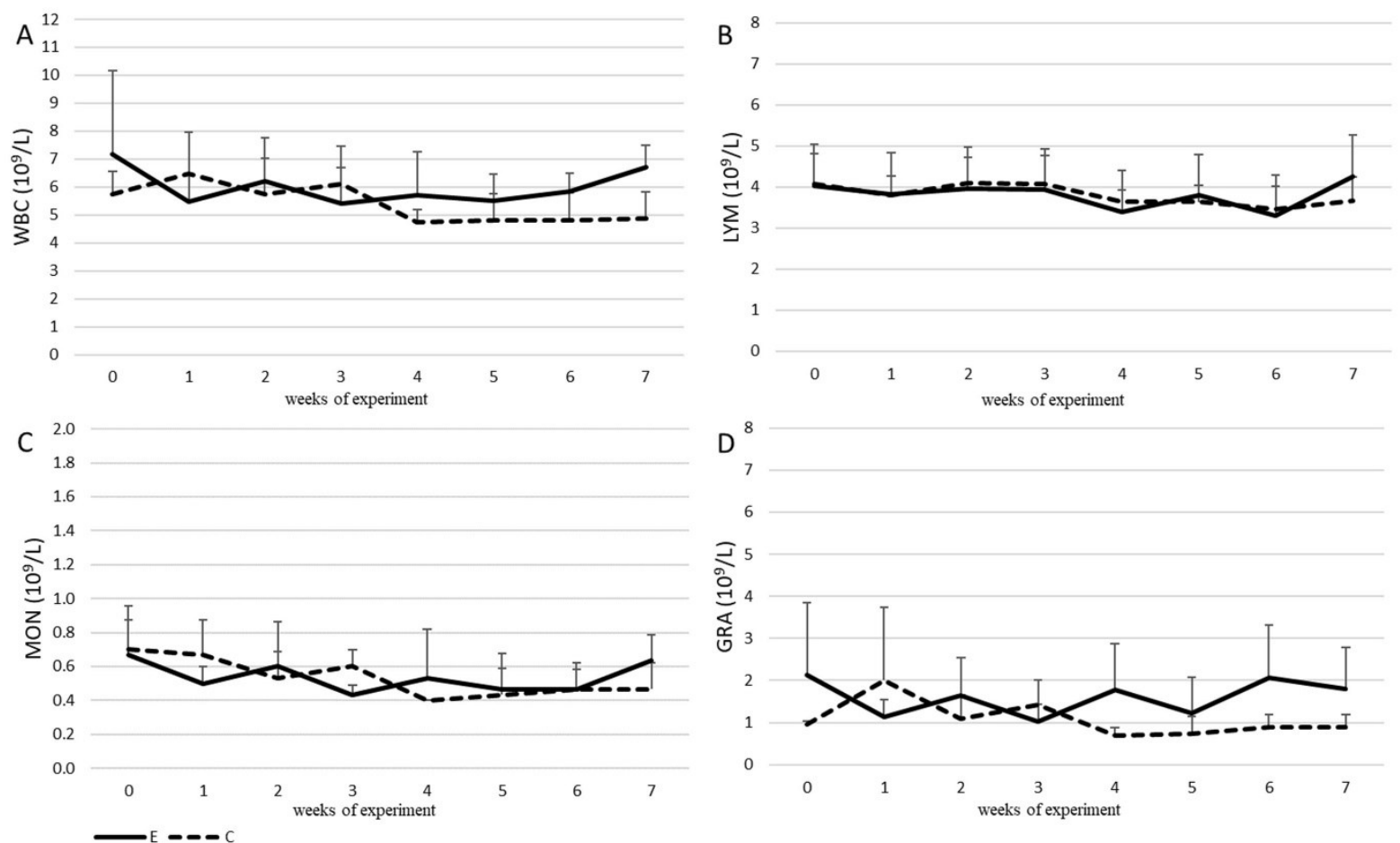

Fig. 1. Results of: $1 \mathrm{~A}$ the total count of white blood cells (WBCs); and differentiated leukocyte counts as 1B lymphocytes (LYM); $1 \mathrm{C}$ monocytes (MON); and 1D granulocytes (GRA) in the peripheral blood of the examined calves. Data are presented as mean $\pm \mathrm{SD}$ 

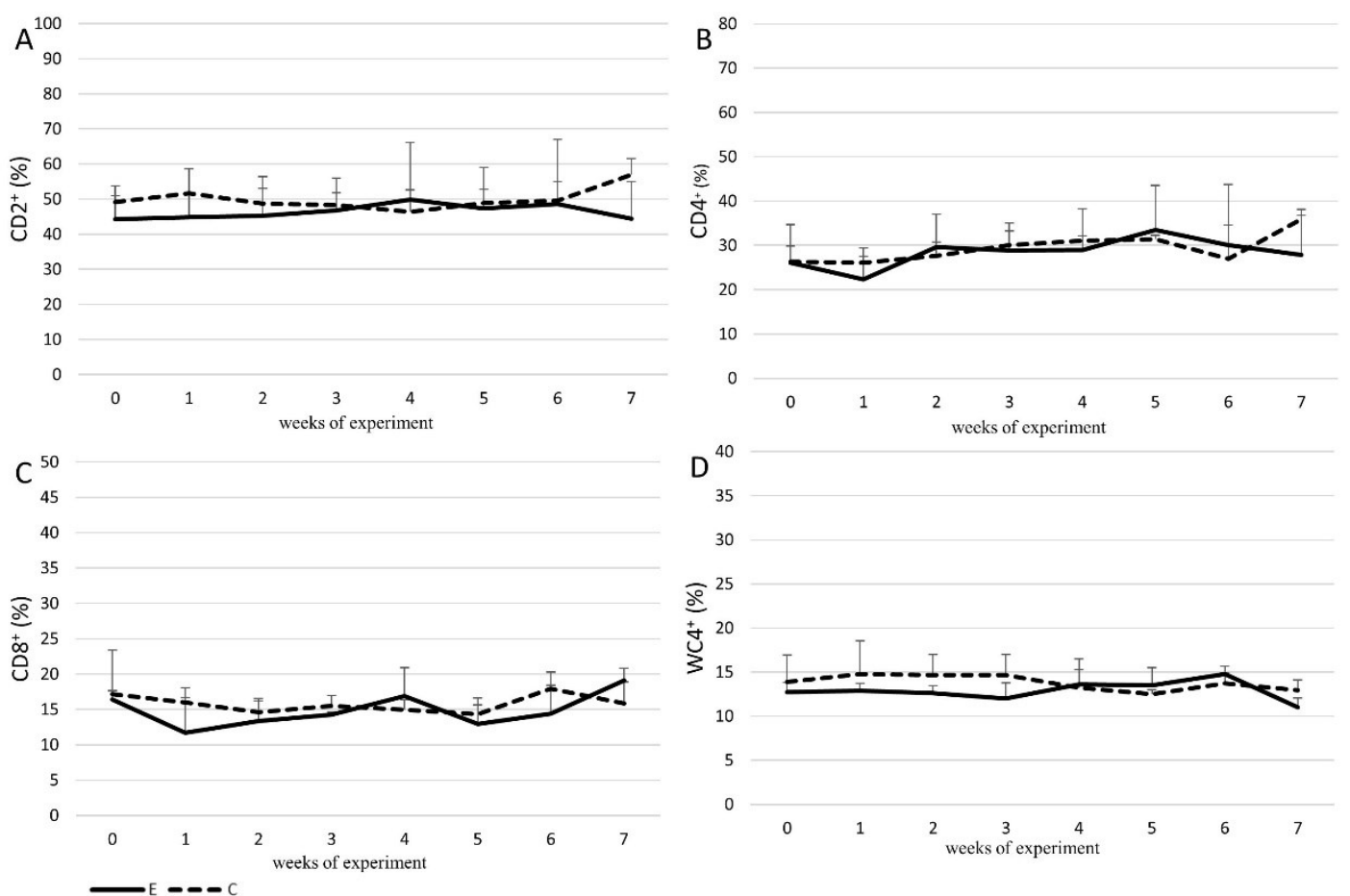

Fig. 2. Percentage of the lymphocyte subpopulations containing various surface antigens: $2 \mathrm{~A} \mathrm{CD} 2^{+} ; 2 \mathrm{~B} \mathrm{CD} 4^{+} ; 2 \mathrm{C} \mathrm{CD} 8^{+}$; and $2 \mathrm{D} \mathrm{WC4} 4^{+}$in the peripheral blood of the examined calves. Data are expressed as mean $\pm \mathrm{SD}$

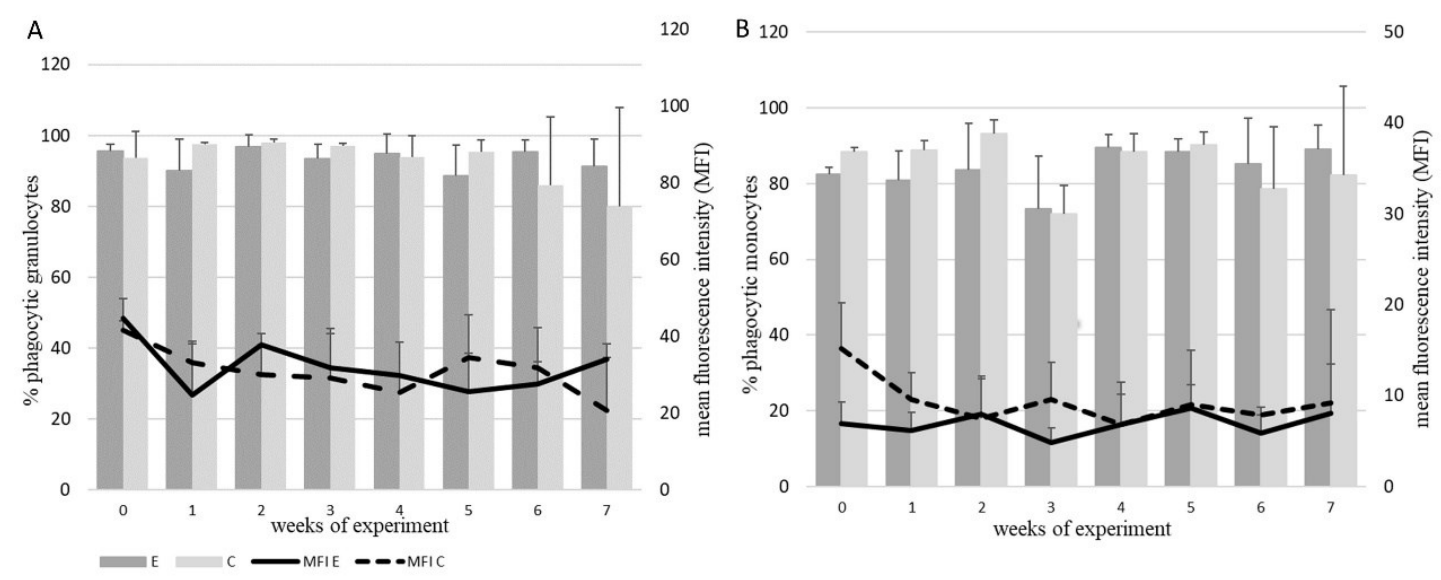

Fig. 3. Cytometric analysis of phagocytic activity of: A - granulocytes and B - monocytes in the peripheral blood of the E and $\mathrm{C}$ calves with values expressed as percentages of phagocytic cells, and with mean fluorescence intensity (MFI) expressed as the index of the phagocytosis intensity of the phagocytic cells. All data are expressed as mean \pm SD

* - Statistically significant differences at $\mathrm{P}<0.05$ compared with the control

120

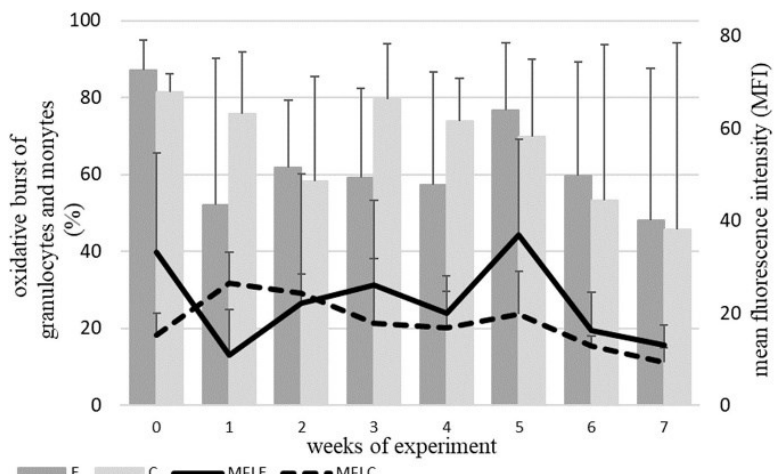

Fig. 4. Cytometric analysis of the oxidative burst activity of the granulocytes and monocytes in the peripheral blood of the calves from the $\mathrm{E}$ and $\mathrm{C}$ groups with values expressed as the percentage of cells that produce reactive oxidants and with the mean fluorescence intensity (MFI) expressed as the index of activity of cells with oxidative burst activity

\section{Discussion}

Due to the complexity of the immune system, in vivo examination will still remain the gold standard. For that reason, in this study the novel feed additive was tested in calves. Its evaluation was based on selected indices of non-specific immune response. The results of the WBC count with leukocyte differentiation and lymphocyte immunophenotyping showed that the tested feed additive did not generally modulate the immune response of the $\mathrm{E}$ group calves. All values were similar to those obtained for the $\mathrm{C}$ group and the WBC counts with leukocyte differentiation were within the physiological ranges. Slight differences between the groups were observed, but they were not statistically significant. In this study, the phagocytic and killing activity of the calves' granulocytes and monocytes during the experiment were assessed. For this purpose, the flow cytometry technique with the adapted Phagotest 
and Phagoburst assays was used, and it provided valuable data concerning the functional status of these cells. Phagocytosis is useful for assessing the status of nonspecific immunity. Monocytes and granulocytes are phagocytes that circulate in the blood and are types of immune cells that can ingest different bacteria and also nanoparticles. The phagocytic activity of monocytes and granulocytes is an indicator of the ability of each examined cell to absorb bacteria, and the MFI illustrates the intensity of this process. No significant changes in the percentage of phagocyting monocytes and granulocytes nor of the relevant average value of the MFI were observed in the $\mathrm{E}$ group calves receiving the novel feed additive when compared with the $\mathrm{C}$ group calves. The oxidative burst of the monocytes and granulocytes and the MFI of this process were also measured in this study. The examination revealed no significant changes of these indices in the E group. Until now, in the literature there has been scarce data about the effects of organic acids and pancreatic enzymes, i.e. lipase, amylase and protease, on the humoral response in calves. In one experiment, weaned pigs were fed with protease and the research revealed that the animals from the experimental group had lower WBC values than those from the negative control group (19). On the other hand, in research by Min et al. (21), no differences were found in $\mathrm{ADG}$ and or WBC between control and experimental animals in a study in which protease with probiotics was administered as a feed additive for pigs.

In our study, a tendency for higher ADG of the supplemented calves was recorded compared to the $\mathrm{C}$ group, although the differences were not statistically significant. These results are in accordance with the research by Salem et al. (35), where steers were fed a mixture of exogenous enzymes, i.e. endoglucanase, alpha-amylase and protease. The steers were fed the enzyme-supplemented diet and had weight gains $16 \%$ higher than control animals. There are also studies that describe the beneficial effect of supplementation with $\alpha$-amylase, $\beta$-mannanase and protease in pigs. Jo et al. (16) presented experimental data in which such supplementation conducted for 28 days resulted in greater ADG. Other research describes the influence of exogenous enzymes on the growth performance of lambs (8). The results of this examination revealed that life weight gain increased by $92 \%$ in lambs fed with ensiled orange pulp and a mixture of exogenous enzymes that contained anaerobic bacteria and their cellulase, xylanase, $\alpha$-amylase and protease enzymes (8). This means that supplementation with exogenous enzymes may improve the performance of growing animals. Acidifiers improve the enzymes' digestive activity, and for that reason this experiment was planned to evaluate the potency of microbe-derived protease and lipase in the presence of protected organic acids. In addition to traditional acidifying additives, encapsulated forms were used in this study. In the process of their production, acid molecules are surrounded with a fat coat, which can be degraded by lipolytic enzymes in the small intestine. In contrast, traditional acidifiers mainly play a role in the stomach without affecting the distal gastrointestinal tract. Protected acidifiers are also useful in the small intestine, because of their elimination of harmful microorganisms and improvement of the status of the microbiota $(28,36)$. The obtained results are consistent with studies on pigs, in which the use of acidifiers and a mixture of organic acids and probiotics positively influenced the feed intake and rearing parameters in this animal species $(15,31)$. Another study reports that piglets fed a mixture of essential oils and organic acids (comprised of cinnamaldehyde, thymol, citric acid, sorbic acid, malic acid and fumaric acid) had improved final body weight (42). On the other hand, another experiment conducted on weaning and postweaning calves concerning the effect on their performance and health status of adding acidifiers such as citric acid, lactic acid, fumaric acid, phosphoric acid and vitamin $\mathrm{C}$ to milk, milk replacer or post-weaning concentrate did not show higher average daily gains in experimental animals (32). However, there are studies which show improvement of the ADG in of calves after dietary butyrate supplementation in milk replacer. For example, Hill et al. (14) examined the addition of sodium butyrate to milk replacer given to Holstein calves that were seven days old. Beneficial effects described in the study are the greater speed at which the experimental calves grew up and the greater ADG they made than the controls. Other research showed that exogenous butyrate could play a role in the improvement of calf performance. In this experiment, HF calves were fed with $0.3,1$ and $3 \%$ sodium butyrate and the experiment was carried out until the calves' $90^{\text {th }}$ day of life. It revealed that the addition of $3 \% \mathrm{Na}$-butyrate to the diet reduced feed intake and had a beneficial effect on calf growth (39). Another experiment revealed that sodium butyrate can be a growth promoter in milk replacer-fed calves. In this study, the experimental calves were fed from 12 to 151 days of life sodium butyrate in the amount of $3 \mathrm{~g} / \mathrm{kg}$ of dry matter and the control calves were fed flavomycin as growth promoter. The results indicated that the experimental group of animals had higher b.w. gains (10).

Different investigations of the toxicity of silica nanoparticles have been conducted on animals in diverse global regions. The influence of silicon nanoparticles (Sn) on the host depends on the size, dose and cell type. There are studies which suggest that nanoparticles of silicon dioxide can have an adverse effect on the immune response and leukocyte function, but that the impact mostly depends on their size, structure, and the route of administration. Some in vitro research shows that only higher doses of $\mathrm{nSiO}_{2}$ can be toxic to cell lines $(11,18)$. Other studies demonstrate the stimulating potential of $\mathrm{nSiO}_{2}$ on the humoral immunity in cattle vaccinated with new vaccine formulations based on a silicon adjuvant. For example, in a study by Mody et al. (23), $\mathrm{Sn}$ elicited antibody stimulation and T-cell-mediated immunity. In their experiment on mice, novel silica 
vesicles with a small particle size of $50 \mathrm{~nm}$ were evaluated as an antigen carrier and adjuvant for bovine viral diarrhoea virus (BVDV) vaccine. It showed a high loading capacity and controlled release of codonoptimised E2 protein, a major immunogenic determinant of BVDV. Although nanotechnology in the livestock sector seems to be very promising, it still warrants further investigation to acquire information still needed. To the best of our knowledge, there are no evaluations of calves' WBC profile and how it varies when nanoparticles of silicon dioxide are added to feed. Although the influence of one product (only $\mathrm{nSiO}_{2}$ ) on animal performance is often intangible, the use of a combination of several different supplements shows a beneficial effect on animal health. There is a study on a similar feed additive to that used in our examination conducted on pigs, where the impact of dietary supplementation with the preparation containing silicon dioxide nanoparticles and pancreatic-like enzymes of microbial origin (protease and amylase) on piglets' performance up to 63 days of age was examined. The use of the additive containing pancreatic-like enzymes together with $\mathrm{nSiO}_{2}$ significantly increased the body weight gained by the piglets during this period. The best results were obtained in the group receiving the additive with $\mathrm{nSiO}_{2}$ and amylase (38). In a study by Pierzynowska et al. (29), the addition of a mixture of pancreatic-like enzymes to the pig diet comprising 120,000 active lipase units, 80,000 active protease units and 12,000 active amylase units was examined and was found to support somatic growth of the experimental pigs. In our study as in most of the studies described above, the beneficial effect of the examined feed additives can be measured by the upward tendency in body weight gains, but in our study the status of the calf immune system was also assessed by the detection of different selected cellular immune parameters.

Based on the immunological parameters analysed, it may be concluded that the examined feed additive did not significantly modulate the immune response of the calves. Additionally, a beneficial effect of using this supplement in calves was the tendency to higher average daily gains in the experimental animals compared with the controls. However, further studies are necessary to better understand the effect of the feed additive on other aspects of physiological processes in cattle.

Conflict of Interests Statement: The authors declare that there is no conflict of interests regarding the publication of this article.

Financial Disclosure Statement: This study was funded by the statutory activity of the National Veterinary Research Institute in Puławy.

Animal Rights Statement: All procedures that included animals were approved by the Local Ethics Commission in Lublin (permission number 68/2018).

\section{References}

1. Aarestrup F.M.: Occurrence, selection and spread of resistance to antimicrobial agents used for growth promotion for food animals in Denmark. APMIS Suppl 2000, 101, 1-48.

2. Bachofen C., Braun U., Hilbe M., Ehrensperger F., Stalder H., Peterhans E.: Clinical appearance and pathology of cattle persistently infected with bovine viral diarrhoea virus of different genetic subgroups. Vet Microbiol 2010, 141, 258-267, doi: 10.1016/j.vetmic.2009.09.022.

3. Baker J.C.: Bovine respiratory syncytial virus: pathogenesis, clinical signs, diagnosis, treatment, and prevention. Compend Food Anim 1986, 8, 31-38.

4. Celi P., Cowieson A.J., Fru-Nji F., Steinert R.E., Kluenter A.-M., Verlhac V.: Gastrointestinal functionality in animal nutrition and health: new opportunities for sustainable animal production. Anim Feed Sci Technol 2017, 234, 88-100, doi: 10.1016/j.anifeedsci.2017.09.012.

5. Chen Y., Gao Y., Yin S., Zhang S, Wang L., Qu Y.-L.: Effect of acidified milk feeding on the intake, average daily gain and fecal microbiological diversity of Holstein dairy calves. AsianAustralas J Anim Sci 2020, 33, 1265-1272, doi: 10.5713/ajas.19.0412.

6. Ferenc M.: Właściwości biologiczne funkcjonalizowanych krzemionek mezoporowatych typu SBA (Biological properties of functionalised mesoporous SbA silica - in Polish). PhD thesis, University of Lodz, Poland, 2016.

7. Friend S.C., Wilkie B.N., Thomson R.G., Barnum D.A.: Bovine pneumonic pasteurellosis: experimental induction in vaccinated and nonvaccinated calves. Can J Comp Med, 1977, 41, 77-83.

8. Gado H.M., Salem A.Z.M., Odongo N.E., Borhami B.E.: Influence of exogenous enzymes ensiled with orange pulp on digestion and growth performance in lambs. Anim Feed Sci Technol 2011, 165, 131-136, doi: 10.1016/j.anifeedsci. 2011.02.016

9. Guilloteau P., Plodari M., Romé V., Savary G., Le Normand L., Zabielski R.: Pancreatic enzyme deficiency depends on dietary protein origin in milk-fed calves. J Dairy Sci 2011, 94, 1517-1525, doi: 10.3168/jds.2010-3906.

10. Guilloteau P., Zabielski R., David J.C., Blum J.W., Morisset J.A., Biernat M., Woliński J., Laubitz D., Hamon Y.: Sodium-butyrate as a growth promoter in milk replacer formula for young calves. J Dairy Sci 2009, 92, 1038-1049, doi: 10.3168/jds.2008-1213.

11. Guo Z., Martucci N.J., Liu Y., Yoo E., Tako E., Mahler G.J.: Silicon dioxide nanoparticle exposure affects small intestine function in an in vitro model. Nanotoxicology 2018, 12, 485-508, doi: 10.1080/17435390.2018.1463407.

12. Herrick K.J., Hippen A.R., Kalscheur K.F., Schingoethe D.J., Casper D.P., Moreland S.C., van Eys J.E.: Single-dose infusion of sodium butyrate, but not lactose, increases plasma $\beta$ hydroxybutyrate and insulin in lactating dairy cows. J Dairy Sci 2017, 100, 757-768, doi: 10.3168/jds.2016-11634.

13. Hill T.M., Aldrich J.M., Schlotterbeck R.L., Bateman H.G. II: Effects of changing the fat and fatty acid composition of milk replacers fed to neonatal calves. Prof Anim Sci 2007, 23, 135-143, doi: 10.15232/S1080-7446(15)30953-0.

14. Hill T.M., Vandehaar M.J., Sordillo L.M., Catherman D.R., Bateman H.G. II, Schlotterbeck R.L.: Fatty acid intake alters growth and immunity in milk-fed calves. J Dairy Sci 2011, 94, 3936-3948, doi: 10.3168/jds.2010-3935.

15. Janik A., Pieszka M.: Effectiveness of probiotic, acidifier and mannan oligosaccharide use in piglet rearing. Ann Anim Sci Suppl 2006, 2, 335-340, doi: 10.22630/AAS.2018.57.4.39.

16. Jo J.K., Ingale S.L., Kim J.S., Kim Y.W., Kim K.H., Lohakare J.D., Lee J.H., Chae B.J.: Effects of exogenous enzyme supplementation to corn- and soybean meal-based or complex diets on growth performance, nutrient digestibility, and blood metabolites in growing pigs. J Anim Sci 2012, 90, 3041-3048, doi: $10.2527 /$ jas.2010-3430. 
17. Kamphues J.: Antibiotic growth promoters for the view of animal nutrition (in German). Berl Munch Tierarztl Wochenschr, 1999, 112, 370-379.

18. Kim J.-H., Kim C.-S., Ignacio R.M.C., Kim D.-H., Sajo M.E.J., Maeng E.H., Qi X.-F., Park S.-E., Kim Y.-R., Kim M.-K., Lee K.-J., Kim S.-K.: Immunotoxicity of silicon dioxide nanoparticles with different sizes and electrostatic charge. Int J Nanomedicine 2014, 9 Suppl 2, 183-193, doi: 10.2147/IJN.S57934.

19. Lee J.J., Kang J., Park S., Cho J.H., Oh S., Park D.-J., Perez-Maldonado R., Cho J.-Y., Park I.-H., Kim H.B., Song M.: Effects of dietary protease on immune responses of weaned pigs. J Anim Sci Technol 2020, 62, 174-179, doi: 10.5187/ jast.2020.62.2.174. Erratum in: J Anim Sci Technol 2020, 62 , 427-428, doi: 10.5187/jast.2020.62.3.427.

20. Mallo J.J., Balfagón A., Gracia M.I., Honrubia P., Puyalto M.: Evaluation of different protections of butyric acid aiming for release in the last part of the gastrointestinal tract of piglets. J Anim Sci 2012, 90, 227-229, doi: 10.2527/jas.53959.

21. Min Y., Choi Y., Choe J., Kim Y., Jeong Y., Kim D., Kim J., Jung H., Song M.: Effects of dietary mixture of protease and probiotics on growth performance, blood constituents, and carcass characteristics of growing-finishing pigs. J Anim Sci Technol 2019, 61, 272-277, doi: 10.5187/jast.2019.61.5.27.

22. Mirosław P., Antos A., Polak M.: Genetic diversity of bovine diarrhea and mucosal disease virus (in Polish). Post Mikrobiol 2017, 56, 389-394.

23. Mody K.T., Mahony D., Zhang J., Cavallaro A.S., Zhang B., Popat A., Mahony T.J., Yu C., Mitter N.: Silica vesicles as nanocarriers and adjuvants for generating both antibody and T-cell mediated immune responses to Bovine Viral Diarrhoea Virus E2 protein. Biomaterials 2014, 35, 9972-9983, doi: 10.1016/j.biomaterials.2014.08.044.

24. Muszyńska B., Szacawa E., Bederska-Łojewska D., Dudek K., Pomierny B., Włodarczyk A., Kała K., Lazur J., Suchocki P., Budziszewska B., Bednarek D., Pieszka M.: Preliminary study on Se-enriched Lentinula edodes mycelium as a proposal of new feed additive in selenium deficiency. PLoS One 2020, 15, e0233456, doi: 10.1371/journal.pone.0233456.

25. Narayan R., Nayak U.Y., Raichur A.M., Garg S.: Mesoporous silica nanoparticles: A comprehensive review on synthesis and recent advances. Pharmaceutics 2018, 10, 118, doi: 10.3390/pharmaceutics10030118

26. Nazari M., Karkoodi K., Alizadeh A.: Performance and physiological responses of milk-fed calves to coated calcium butyrate supplementation. S Afr J Ani Sci 2012, 42, 296-303, doi: 10.4314/sajas.v42i3.12

27. Pathakoti K., Goodla L., Manubolu M., Hwang H.-M.: Chapter 3 , Nanoparticles and their potential applications in agriculture, biological therapies, food, biomedical and pharmaceutical industry: A review. In: Nanotechnology and Nanomaterial Applications in Food, Health, and Biomedical Sciences, edited by D.K. Verma, M.R. Goya, H.A.R. Suleria, CRC Press New York, NY, USA, 2019, pp. 121-162.

28. Pearlin B.V., Muthuvel S., Govidasamy P., Villavan M., Alagawany M., Farag M.R., Dhama K., Gopi M.: Role of acidifiers in livestock nutrition and health: A review. J Anim Physiol Anim Nutr 2020, 104, 558-569, doi: 10.1111/jpn.13282.

29. Pierzynowska K., Valverde-Piedra J., Szymanczyk S., Prykhod'ko O., Pieszka M., Kardas M., Grochowska-Niedworok E., Grabowski T.,
Winiarczyk M., Pierzynowski S.: Pancreatic-like enzymes of microbial origin restore growth and normalize lipid absorption in a pig model with exocrine pancreatic insufficiency. Arch Med Sci 2018, 14, 407-414, doi: 10.5114/aoms.2018.73471.

30. Pietroiusti A., Magrini A., Campagnolo L.: New frontiers in nanotoxicology: gut microbiota/microbiome-mediated effects of engineered nanomaterials. Toxicol Appl Pharmacol 2016, 299, 90-95, doi: 10.1016/j.taap.2015.12.017

31. Rekiel A., Kulisiewicz J.: The use of acidifying and probiotic preparates in piglet rearing (in Polish). Med Wet 1996, 52, 266-269.

32. Ribeiro M.D., Pereira J.C., de Queiroz A.C., Cecon P.R., Detmann E., Azevêdo J.A.G.: Performance of dairy calves fed milk, milk replacer or post-weaning concentrate with acidifiers. Rev Bras Zootec 2009, 38, 956-963, doi: 10.1590/S151635982009000500024.

33. Rice J.A., Carrasco-Medina L., Hodgins D.C., Shewen P.E. Mannheimia haemolytica and bovine respiratory disease. Anim Health Res Rev 2007, 8, 117-128, doi: 10.1017/S1466252307001375.

34. Roxas M.: The role of enzyme supplementation in digestive disorders. Altern Med Rev 2008, 13, 307-314.

35. Salem A.Z.M., Gado H.M., Colombatto D., Elghandour M.M.Y.: Effects of exogenous enzymes on nutrient digestibility, ruminal fermentation and growth performance in beef steers. Livest Sci 2013, 154, 69-73, doi: 10.1016/j.livsci.2013.02.014.

36. Smulikowska S., Czerwiński J., Mieczkowska A., Jankowiak J.: The effect of fat-coated organic acid salts and a feed enzyme on growth performance, nutrient utilization, microflora activity, and morphology of the small intestine in broiler chickens. J Anim Feed Sci 2009, 18, 478-489, doi: 10.22358/jafs/66422/2009.

37. Szacawa E., Niemczuk K., Dudek K., Bednarek D., Rosales R., Ayling R.D.: Mycoplasma bovis infections and co-infections with other Mycoplasma spp. with different clinical manifestations in affected cattle herds in eastern region of Poland. Bull Vet Inst Pulawy 2015, 59, 331-337, doi: 10.1515/bvip-2015-0049.

38. Szczurek P., Kamyczek M., Pierzynowski S., Goncharova K., Michałowski P., Weström B., Pryhodko O., Grabowski T., Pieszka M.: Effects of dietary supplementation with pancreaticlike enzymes of microbial origin (PLEM) and silicon dioxide $\left(\mathrm{SiO}_{2}\right)$ on the performance of piglets fed creep feed. J Anim Sci 2016, 94, 62-65, doi: 10.2527/jas.2015-9607.

39. Ślusarczyk K., Strzetelski J.A., Furgał-Dierżuk I.: The effect of sodium butyrate on calf growth and serum level of $\beta$-hydroxybutyric acid. J Anim Feed Sci 2010, 19, 348-357, doi: $10.22358 / \mathrm{jafs} / 66298 / 2010$.

40. Tricarico J.M., Johnston J.D., Dawson K.A.: Dietary supplementation of ruminant diets with an Aspergillus oryzae $\alpha$-amylase. Anim Feed Sci Technol 2008, 145, 136-150, doi: 10.1016/J.ANIFEEDSCI.2007.04.017.

41. Wojcicka-Lorenowicz K., Kostro K., Lisiecka U., Gąsiorek B.: Phagocytic activity and oxygen metabolism of peripheral blood granulocytes from rabbits experimentally infected with Trichophyton mentagrophytes. J Vet Res 2018, 62, 43-48, doi: 10.2478/jvetres-2018-0006

42. Yang C., Zhang L., Cao G., Feng J., Yue M., Xu Y., Dai B., Han Q., Guo X.: Effects of dietary supplementation with essential oils and organic acids on the growth performance, immune system, fecal volatile fatty acids, and microflora community in weaned piglets. J Anim Sci 2019, 97, 133-143, doi: 10.1093/jas/sky426. 